\title{
A modified controlled cortical impact technique to model mild traumatic brain injury mechanics in mice
}

\author{
YungChia Chen ${ }^{1}$, Haojie Mao ${ }^{2}$, King H. Yang ${ }^{2}$, Ted Abel $^{3}$ and David F. Meaney ${ }^{1}$ * \\ ${ }^{1}$ Department of Bioengineering, University of Pennsylvania, Philadelphia, PA, USA \\ ${ }^{2}$ Bioengineering Center, Wayne State University, Detroit, MI, USA \\ ${ }^{3}$ Department of Biology, University of Pennsy/vania, Philadelphia, PA, USA
}

Edited by:

Mattias K. Sköld, Uppsala University, Sweden

\section{Reviewed by:}

Stefan Plantman, Karolinska

Institutet, Sweden

Anders Hånell, Virginia

Commonwealth University, USA

*Correspondence:

David F. Meaney, Department of Bioengineering, University of

Pennsylvania, 210 S 33rd Street, 240

Skirkanich Hall, Philadelphia, PA

19104, USA

e-mail:dmeaney@seas.upenn.edu
For the past 25 years, controlled cortical impact (CCI) has been a useful tool in traumatic brain injury (TBI) research, creating injury patterns that includes primary contusion, neuronal loss, and traumatic axonal damage. However, when $\mathrm{CCl}$ was first developed, very little was known on the underlying biomechanics of mild TBI. This paper uses information generated from recent computational models of mild TBI in humans to alter $\mathrm{CCl}$ and better reflect the biomechanical conditions of mild TBI. Using a finite element model of $\mathrm{CCl}$ in the mouse, we adjusted three primary features of $\mathrm{CCl}$ : the speed of the impact to achieve strain rates within the range associated with mild TBI, the shape, and material of the impounder to minimize strain concentrations in the brain, and the impact depth to control the peak deformation that occurred in the cortex and hippocampus. For these modified cortical impact conditions, we observed peak strains and strain rates throughout the brain were significantly reduced and consistent with estimated strains and strain rates observed in human mildTBI. We saw breakdown of the blood-brain barrier but no primary hemorrhage. Moreover, neuronal degeneration, axonal injury, and both astrocytic and microglia reactivity were observed up to 8 days after injury. Significant deficits in rotarod performance appeared early after injury, but we observed no impairment in spatial object recognition or contextual fear conditioning response 5 and 8 days after injury, respectively. Together, these data show that simulating the biomechanical conditions of mild TBI with a modified cortical impact technique produces regions of cellular reactivity and neuronal loss that coincide with only a transient behavioral impairment.

Keywords: controlled cortical impact, mild traumatic brain injury, biomechanics, strain rate, glia reactivity

\section{INTRODUCTION}

Traumatic brain injury (TBI) is a significant public health problem. Of the 1.7 million people diagnosed with TBI, about $75 \%$ of them are considered to have experienced mild traumatic brain injury (mTBI) (1). Although most mTBI patients do not have long term impairments (2) approximately $15 \%$ may experience symptoms for years, and these persisting deficits are a major contributor to the morbidity associated with the disease $(3,4)$. Current diagnosis for TBI relies on clinical assessment; (5-7) neuroimaging techniques such as computed axial tomography (CT), magnetic resonance imaging (MRI), and diffusion tensor imaging (DTI) are all used to better detect structural and functional changes in TBI patients (8-10). Diagnosis for mTBI is more difficult than either moderate or severe TBI, due in part to the rapid recovery of symptoms and the lack of a universal definition (11-14). However, once diagnosed, there are very few treatment options outside of rehabilitation; successful pre-clinical treatments have yet to translate to the clinical population (15).

Creating an experimental model to reproduce faithfully human mTBI is challenging, yet can offer an important new tool to study mTBI in the laboratory. Re-creating the biomechanics of the tissue loading in the brain during injury is one key part of modeling mild TBI. In the past 10 years, biomechanics research successfully coupled finite element analyses (FEA) to existing TBI models and human accident reconstructions to produce a more detailed picture of the in vivo mechanical loading associated with concussions (16-22). These computational models analyzed the relationship between mechanical stress/strain and resulting structural/functional damage to tissue (23-36) to provide estimates on injury volume and mechanical injury thresholds for specific loading conditions (20,37-42). In parallel, physical models of the brain also offered estimates of the tissue biomechanics associated with injury in the white matter $(24,25,43)$. Among rodent mTBI models, strain rates of fluid percussion (FPI) and the dynamic cortical deformation injury models have similar ranges estimated in human mTBI (Figure 1) $(37,44,45)$. Closed head injury rodent models may also yield strains and strain rates in the range of human TBI (46-55). Computational models of the brain mechanical response to either FPI and closed impact are difficult to develop, though, as some of the mechanical interactions in these models are difficult to quantify. Recently, a coronal rotational head injury in the rodent that uses accelerations scaled from human TBI was created and simulated in a two-dimensional finite element model $(52,56)$. However, this diffuse brain injury (DBI) model failed to show only axonal histopathological changes that are considered the hallmark for human mTBI; $(57,58)$ over $50 \%$ of the animals 

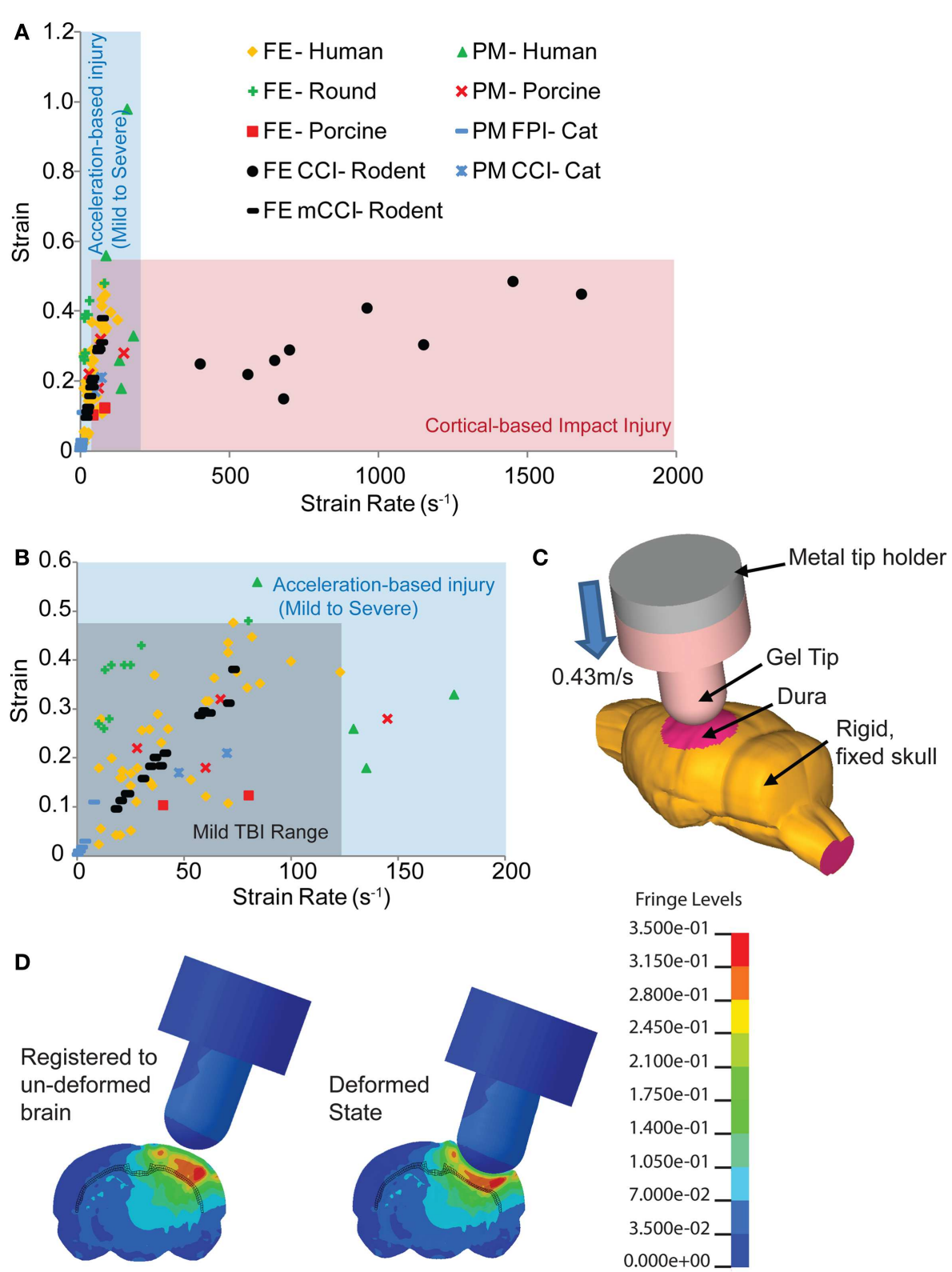

FIGURE 1 | Comparison of estimated strains and strain rates occurring in the brain from human-based and animal-based studies of brain

biomechanics. (A) The range of controlled cortical impact (CCI) brain injury extends over a much broader range of strain rates compared to those found in human and other animal TBI models. (B) A range of studies for the tissue loading conditions associated with mild TBI in humans provides a design corridor for modifying the cortical impact model to reproduce these mild TBI conditions in the mouse. (C) A finite element model of the mouse cortical impact model was used to study the tissue strain and strain rates that appear in the cortex and hippocampus when both impact depth and velocity are varied. The range of conditions for $0.43 \mathrm{~m} / \mathrm{s}, 2 \mathrm{~mm}$ impact depth appears in (B) (black filled circles), while (D) shows the strain distribution of a mouse brain subject to these cortical impact conditions. References used: FE-Human (20, 39, 59-64), FE-Round (65), FE-Porcine (66); PM-Human (23), PM-Primate (24), PM-Porcine (43), FE CCI-Rodent (67, 68), PM CCI-Cat (69), PM FPI-Cat (45). FE, finite element; PM, physical model. had hemorrhaging and lesions, pathologies that are not typical of mTBI.

With its precise impounder shape, impact depth, and controlled velocity, the controlled cortical impact (CCI) model is often the most direct model to study the biomechanics of TBI with a computationally based finite element model. The bulk of rodent TBI finite element models study the CCI technique $(19,67,70,71)$. However, even at slower speeds, CCI produces strain rates in the brain tissue of $400 \mathrm{~s}^{-1}$ and over (68) well over the higher strain rates of moderate to severe human TBI (Figure 1). At the more typical speeds, tissue strain rates range from 1150 to $1450 \mathrm{~s}^{-1}$ (67). Therefore, we revisited the biomechanics of traditional rodent $\mathrm{CCI}$, altering it to produce injury conditions in the rodent that better approximate the brain tissue loading rates seen in human mTBI. To achieve this 
design goal, the impact velocity was reduced to achieve tissue strain rates more consistent with mild TBI, the cortical impact tip modified to distribute the strains throughout the cortex, and the impact depth adjusted accordingly. The combination of reducing impact velocity (strain rate) while maintaining impact depth (strain) created an injury pattern that included blood-brain barrier (BBB) opening, traumatic axonal injury, astrocyte reactivity, neuronal degeneration, and microglial activation without the significant hemorrhage and necrotic lesion often associated with cortical impact. Moreover, this modification achieves a slight, but temporary, behavioral deficit. The improved biomechanical fidelity of this model now provides a new tool to determine the tissue tolerance criteria associated with neuronal and glial changes in the brain after mTBI, as well as a scientific tool to compare the effects between a hemorrhagic and non-hemorrhagic injury.

\section{MATERIALS AND METHODS MODIFIED CCI DEVICE}

The traditional controlled cortical impact (tCCI) for the mouse (72) produces a reproducible, graded injury that is influenced by the impounder shape, velocity, and depth of impact. The mild controlled cortical impact modified CCI (mCCI) model we designed retains many features of tCCI: an impounder strikes the exposed cortical surface, the impounder is returned to its original position, and the size of the craniotomy is within the range used in past cortical impact studies. Two main differences are the use of a rounded silicone tip ( $4 \mathrm{~mm}$ diameter; tip was made by injecting Sylgard 184 - mixed and vacuumed - into a 3-D printed mold) and adjusting the impact speed to reproduce the tissue loading biomechanics that occur in mild TBI. A rounded tip was chosen over the traditional, rounded cylindrical tip to minimize the hemorrhaging. A cylindrical shaped indentor has been shown to cause greater maximum principal strains and generate greater cortical hemorrhage than a rounded tip in traditional CCI $(71,73)$.

To develop a more precise estimate of impact velocity needed to achieve the tissue strain rates for mild TBI, we built a finite element model of the mouse brain and indentor used in the cortical impact technique. The finite element model (Figure 1C) incorporated a $4.5-\mathrm{mm}$ craniotomy located on the left hemisphere, midway between bregma and lambda. The center of the impact was located at $-2.5 \mathrm{~mm}$ bregma with a $20^{\circ}$ angle of impact. An initial gap of $0.1 \mathrm{~mm}$ appeared between the gel tip and the exposed dura. To simulate injury, the rigid metal holder moved $2.1 \mathrm{~mm}$ downward into the model brain at $0.43 \mathrm{~m} / \mathrm{s}$. The finite element mouse brain model used was a previously validated model from Pleasant et al. (73). The silicone gel tip indentor was modeled using Ogden constitutive law available in LS-DYNA (LSTC, Livermore, CA, USA) with material properties from Lusardi et al. (74). For simplicity, only one combination of impact velocity $(0.43 \mathrm{~m} / \mathrm{s})$ and impact depth $(2 \mathrm{~mm})$ was used. The range of resulting strain rates for elements within the hippocampus, cortex, and subcortical white matter of the ipsilateral hemisphere for a $2-\mathrm{mm}, 0.43 \mathrm{~m} / \mathrm{s}$ impact was $12-75 \mathrm{~s}^{-1}$ (black filled circles, Figure 1B). The larger impact diameter and increased impact depth creates a larger volume of tissue deformation (Figures 1C,D).

Using this as a guide, we constructed a modified cortical impact device on a mounting frame to minimize vibration during impact, and to align the indentor in the impact plane (Figure 2). A linear potentiometer (LP803-1, Omega, USA) measured the actuation of the solenoid and a custom Matlab (Mathworks, MA, USA) program controlled the solenoid and collected the potentiometer readings. The impactor was aligned $20^{\circ}$ from vertical (measured with a digital angle meter), similar to other lateral CCI models. We also used a dwell time - defined as the duration over which the indentor is compressed into the brain - within the ranges (25$250 \mathrm{~ms}$ ) for rodent CCI as cited in the literature (75). We could achieve higher impact speeds (4-6 m/s) if desired (Figure 2C), but chose to focus most of our efforts on the slower impact speed. At this lower impact speed, we saw no evidence of tissue necrosis 8 days after impact injury, unlike the extensive necrotic cavity that would appear after an impact using more commonly used impact speeds (4-6 m/s; Figure 2D).

\section{CORTICAL INJURY}

All animal procedures were approved by University of Pennsylvania's Institutional Animal Care and Use Committee (IACUC). Sixty 10-12-week-old male C57Bl6 mice (Jackson) were divided into sham and injured for three different timepoints. A 1-h timepoint to determine extravasation ( $\operatorname{sham}=3$, injured $n=6$ ); 24 -h timepoint to determine early neurodegeneration ( injured $n=10$ each); 8-day timepoint to determine longer term behavioral and histopathological changes ( $\operatorname{sham} n=17$, injured $n=19$ ).

On the day of injury, mice were anesthetized with isoflurane (5\% induction, $2 \%$ maintenance in medical grade air) and placed in a stereotaxic frame on a heating pad to maintain body temperature. A 4-mm diameter craniotomy was produced on the left hemisphere, midway between bregma and lambda. CCI injuries were produced with a modified impactor at a speed of $0.43 \mathrm{~m} / \mathrm{s}$ to a cortical impact depth of $2 \mathrm{~mm}$ (Figures 2B,C). The estimated center of the impact was $-2.5 \mathrm{~mm}$ bregma. The solenoid has a full stroke length of $4 \mathrm{~mm}$. The baseline point was set by lowering the impactor tip to the cortex with the solenoid in the fully actuated position and the linear stage position set to zero. Once baseline was set, the impactor was retracted and the impact depth was adjusted using $1.0 \mathrm{~mm}$ shims. We used a $2.0-\mathrm{mm}$ impact depth for all studies presented in this paper. After injury, the cranial exposure was sutured close and the animals were placed in a warmed cage to recover until ambulatory. All animals survived the injury and surgery.

\section{HISTOLOGY}

Mice were anesthetized with an overdose of sodium pentobarbital. Animals were transcardially perfused with $30 \mathrm{~mL}$ of ice-cold phosphate-buffered saline (PBS) (pH 7.4) and then with $40 \mathrm{~mL}$ of ice-cold $4 \%$ paraformaldehyde. Brains were harvested, post-fixed overnight in $4 \%$ paraformaldehyde at $4^{\circ} \mathrm{C}$, and then cryoprotected in $24 \%$ sucrose. Brains were mounted in Tissue-Tek ${ }^{\circledR}$ and frozen in isopentane cooled with dry ice. Brains were cryosectioned at $20 \mu \mathrm{m}$. Sections were taken $500 \mu \mathrm{m}$ apart starting from bregma -1.5 to $-3.5 \mathrm{~mm}$, therefore spanning the entire lesion area.

\section{Blood-brain barrier compromise}

For identification of extravasation, animals were injected with Evans blue (EB, $100 \mu \mathrm{L}$ of $4 \%$ ) $15 \mathrm{~min}$ prior to the injury or sham 
A

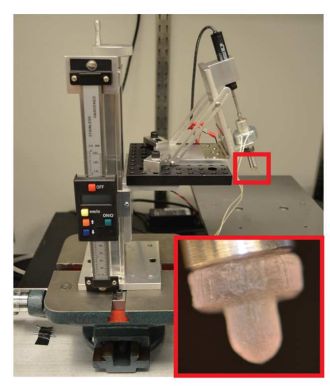

C

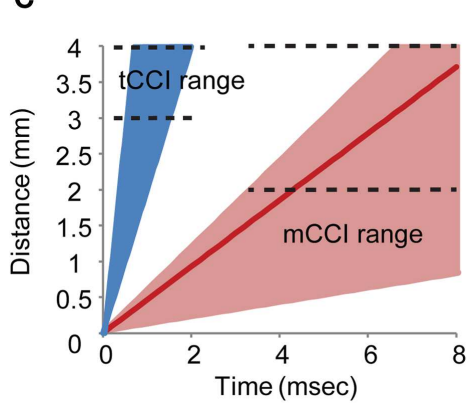

B

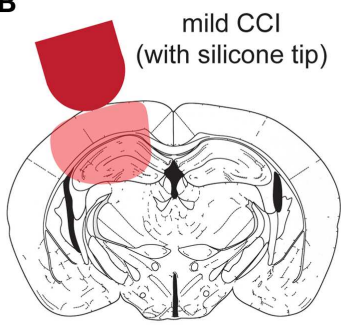

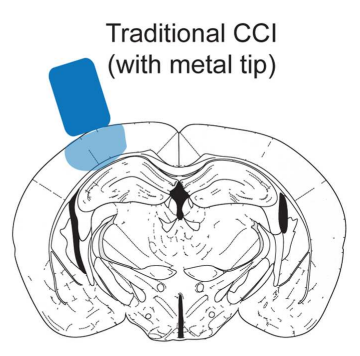

D
$\mathbf{F}$

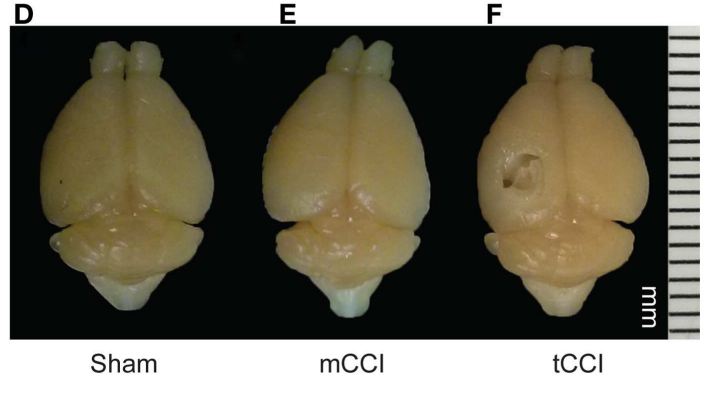

FIGURE 2 | Parameters of mild $\mathbf{C C l}$. The mild $\mathrm{CCl}(\mathrm{mCCl})$ uses a hemispherical silicone tip, actuated by a solenoid (A). A potentiometer records the displacement of the impactor, while the angle and height of the impactor are fully adjustable. A comparison of displaced tissue volume between mild $\mathrm{CCl}$ ( $2 \mathrm{~mm}$ impact depth, $0.43 \mathrm{~m} / \mathrm{s}$ impact velocity) and traditional $\mathrm{CCl}$ (1 $\mathrm{mm}$ impact depth, $4-6 \mathrm{~m} / \mathrm{s}$ impact velocity) is shown in (B).
(C) Shows the range of impact speeds between $\mathrm{tCCl}(2.0-6.0 \mathrm{~m} / \mathrm{s})$ and the velocity range that would generate clinical TBI strain rates $\left(17-104 \mathrm{~s}^{-1}\right.$ for $0.1-0.6 \mathrm{~m} / \mathrm{s}$, respectively). The red line is the impactor speed used in this study $\left(0.43 \mathrm{~m} / \mathrm{s}\right.$ for a strain rate of approximately $\left.75 \mathrm{~s}^{-1}\right)$. Brains perfused 8 days after a sham injury (D), $\mathrm{mCCl}$ with $2 \mathrm{~mm}$ impact depth (E), and $\mathrm{tCCl}$ with an impact depth and speed of $1 \mathrm{~mm}$ and $6.0 \mathrm{~m} / \mathrm{s}$, respectively (F). surgery. One hour post injury, animals were perfused. Brains were removed, post-fixed, cyroprotected, and frozen. Equally spaced, serial tissue sections of the brain were mounted on slides and rinsed several times in PBS. The slides were coverslipped with ProLong Gold (Invitrogen, USA; \#P36934). Sections were imaged with a Leica SP5 confocal microscope (Leica, Germany). The same laser settings were used with all sections.

\section{Neuronal degeneration}

Fluoro-Jade ${ }^{\circledR}$ B (FJB) labeling detected degenerating neurons. Histological sections were rehydrated in graded ethanols (100, $95,80,70 \% ; 2 \mathrm{~min}$ each) followed by distilled water. They were then incubated in a solution of $0.06 \%$ potassium permanganate on a rotating stage for $20 \mathrm{~min}$. The sections were then rinsed in distilled water for $2 \mathrm{~min}$ and placed in fresh $0.0005 \%$ FJB solution made by adding $5 \mathrm{~mL}$ of a $0.01 \%$ stock solution of FJB to $95 \mathrm{~mL}$ of $0.1 \%$ acetic acid. After $30 \mathrm{~min}$ in the FJB staining solution, the sections were rinsed through three changes of distilled water for 1 min per change. Excess water was drained onto a paper towel, and the sections were then air dried in an oven at $37^{\circ}$ for $30 \mathrm{~min}$. The dry sections were cleared by immersion in xylene for at least 2 min before coverslipping with permount (Fisher Scientific, USA). The sections were viewed with a Leica SP5 confocal microscope (Leica, Germany). Positive FJB cell was determined with the same threshold across all images and the number of cells counted with ImageJ.

\section{Astrocyte and microglial reactivity}

Sections were rehydrated in $1 \times$ PBS $(3 \times 5 \mathrm{~min})$ and then incubated with $10 \%$ normal goat serum for 30 min with $0.1 \%$ triton-X. To measure astrocyte reactivity, sections were incubated overnight at room temperature in polyclonal anti-glial fibrillary acidic protein (GFAP) (Neuromics, MN, USA; \#CH22102; 1:500). Images were taken with a Leica DFC340 FX (Leica, Germany) at three different locations for each brain region and the percent area above fluorescence threshold was averaged for each animal. The same settings were used for all sections. Microglial migration and reactivity as well as infiltrating macrophages were assessed using the polyclonal anti-Iba-1 (Wako, VA, USA; \#019-19741; 1:1000). After rinsing with $1 \times \mathrm{PBS}$, sections were then incubated with Alexa 546 conjugated secondary antibodies (Invitrogen, USA; \#A-11035; $1: 250)$ for $1 \mathrm{~h}$ at room temperature. Sections were mounted with ProLong Gold antifade (Invitrogen, USA; \#P36934).

\section{Axonal injury}

Sections were dried and washed in $0.1 \mathrm{M}$ TBS for $5 \mathrm{~min}$. Sections were heated in $10 \mathrm{mM}$ sodium citrate at $75^{\circ} \mathrm{C}$ for $30 \mathrm{~min}$ and allowed to cool to room temperature. Endogenous peroxidase activity was blocked with incubation in 3\% hydrogen peroxide in methanol for $30 \mathrm{~min}$ with shaking. Sections were rinsed with running water for $10 \mathrm{~min}$, after which they were placed in blocking buffer ( $0.1 \mathrm{M}$ TBS and 2\% FBS) for $5 \mathrm{~min}$ before blocking with $10 \%$ NGS for $30 \mathrm{~min}$ in $0.1 \mathrm{M}$ TBS with $0.2 \%$ Triton-X. This was followed by overnight incubation at $4^{\circ} \mathrm{C}$ with anti-amyloid 

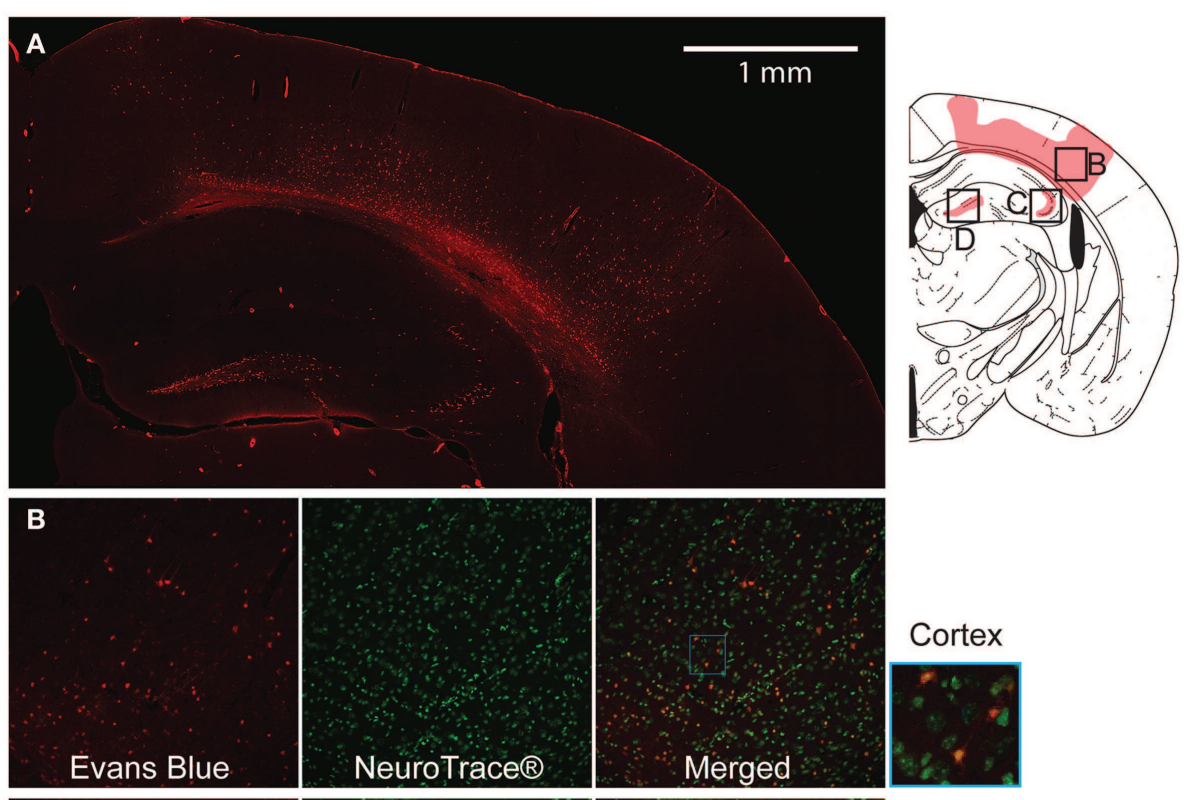

Cortex
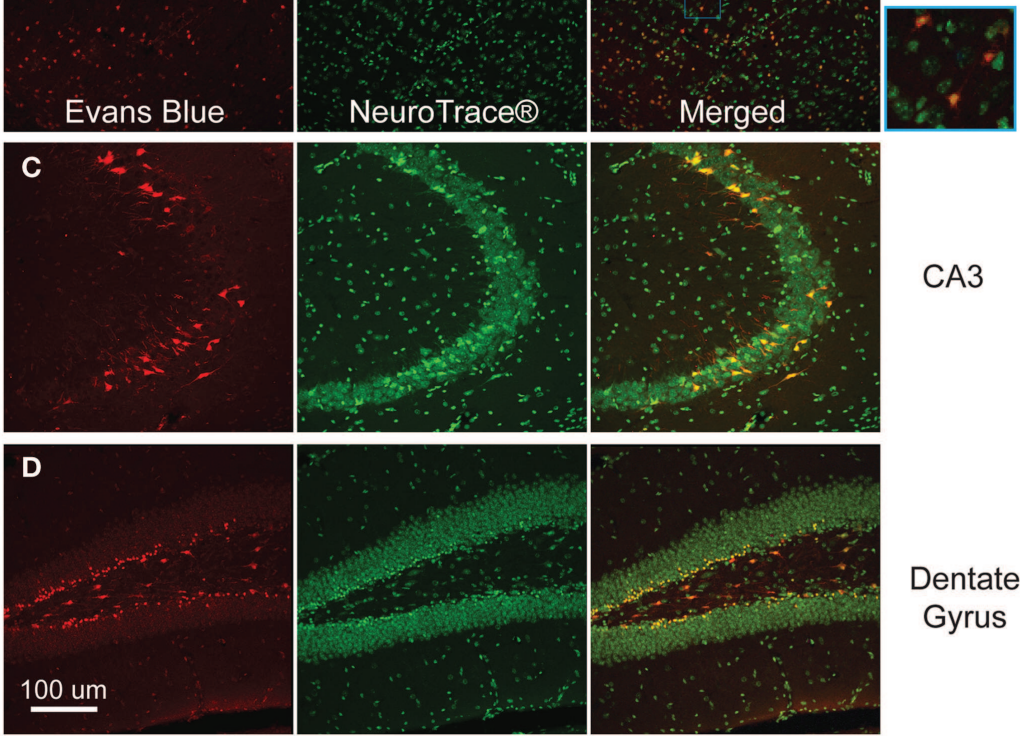

CA3

Dentate

Gyrus

FIGURE 3 | Mild controlled cortical impact induces extravasation of the blood-brain barrier (BBB) at the injured region. The pattern of extravasation is shown and pictorially depicted (A). Co-labeling of EB and Neurotrace ${ }^{\circledR}$ for the cortex (B), CA3 (C), and dentate gyrus (D) show that the EB positive cells are mostly neurons.

precursor protein (APP) (Invitrogen, USA; \#36-3900; 1:1000). Sections were washed in $0.1 \mathrm{M}$ TBS, placed in blocking buffer and then incubated in biotinylated goat anti rabbit secondary (Jackson Labs, \#111-065-003; 1:250). Sections were washed and placed in blocking buffer again prior to incubation in Elite ABC (Vectastain, CA, USA; \#PK-6100) for $30 \mathrm{~min}$. Sections were washed and incubated in DAB (Vectastain, CA, USA; \#SK-4100) for $5 \mathrm{~min}$. Sections were washed in running water for $5 \mathrm{~min}$ and stained with Hematoxylin for $30 \mathrm{~s}$. Sections were washed, dehydrated (alcohol 70, 80, $95 \% 2 \times, 100 \% 2 \times$, xylene $2 \times$ ), and coverslipped in Permount. Images were taken with a Leica DFC500 (Leica, Germany) and the number of varicosities were counted with ImageJ.

\section{BEHAVIOR TESTS}

A series of behavior tests were conducted in the order that placed the test that required the least of amount of mouse handing first and the most stressful test last (Figure 8A). The rotarod training was conducted the day before the injury. On the day of injury, no behavioral test was given. On days 1-3 after injury, mice were tested on the rotarod; on days $4-5$, mice were tested on the spatial object recognition (SOR); on days $7-8$, mice were trained and tested in contextual fear conditioning (CFC).

\section{Cortical motor function}

The rotarod protocol was adapted from Oliveira et al. (76). In short, the rotarod apparatus (Med Associates Inc., VT, USA) has a $3.2-\mathrm{cm}$ diameter rotating rod raised $16.5 \mathrm{~cm}$ above a platform and divided into five sections for testing multiple mice simultaneously. The rotarod gradually increased its rotation speed from 4 to $40 \mathrm{rpm}$ over the course of $5 \mathrm{~min}$. Latency to first fault (defined as the mouse riding with the platform in a single rotation) and fall time was recorded. Mice were trained on the rotarod at $4 \mathrm{rpm}$ 

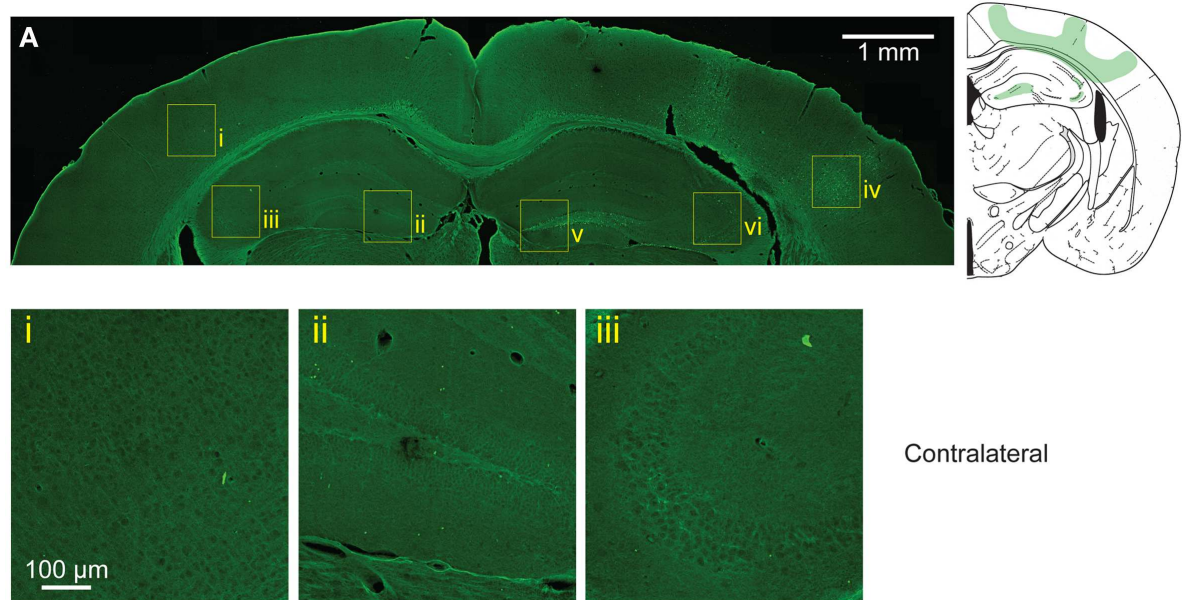

Contralateral
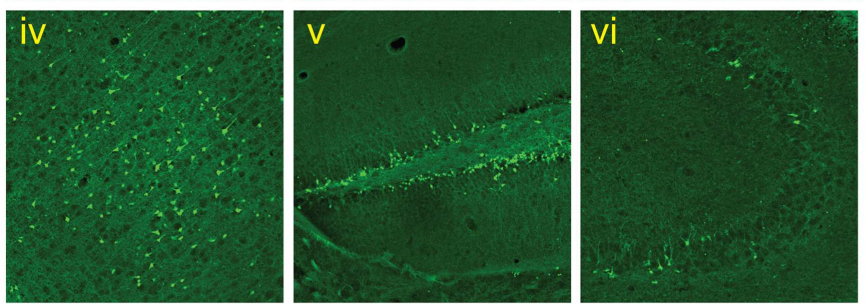

Ipsilateral

B
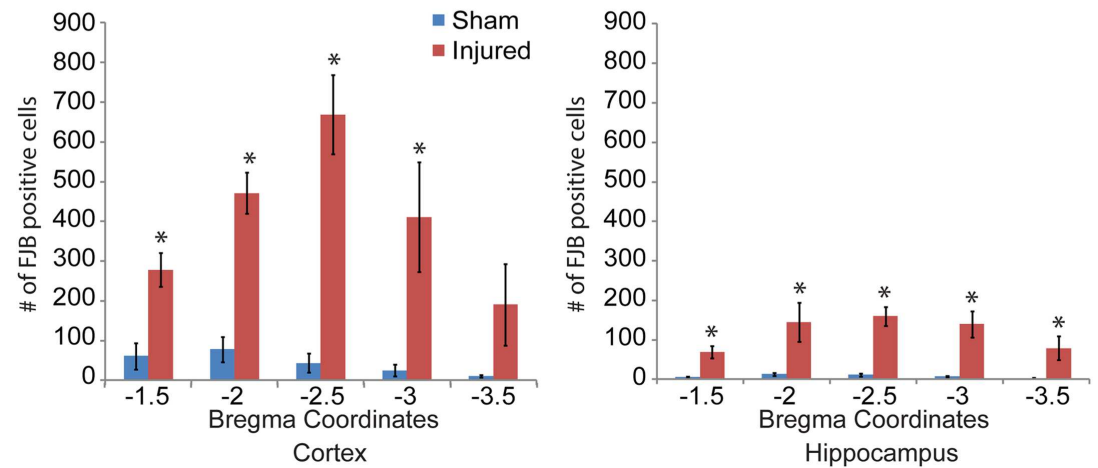

FIGURE 4 | Neuronal degeneration appears $24 \mathrm{~h}$ following mild controlled cortical impact. Fluoro-Jade B (FJB) positive cells appeared in the cortex (iv), dentate gyrus (v), and CA3 (vi) on the ipsilateral side; no labeling was observed in the contralateral hemisphere [(i-iii), respectively] (A). (B) The number of FJB positive cells in injured animals was significantly increased

compared to sham in both the cortical and hippocampal regions for bregma sections -1.5 to -3.0 (cortex $p<0.001$ for each section -1.5 to -3.0 , for section $-3.5 p=0.0635$, hippocampus $p=0.0113$ for section $-1.5, p<0.001$ for sections -2.0 to $-3.5 ; n=5$ sham, $n=10$ injured). Data are expressed as media \pm SEM.

for $60 \mathrm{~s} 1$ day before injury. Three trials a day were given during three consecutive days with an inter-trial interval of $1 \mathrm{~h}$. Each trial started at the same time every day and ended when mice fell or when mice ran for $300 \mathrm{~s}$.

\section{Hippocampal function}

The SOR protocol was adapted from in Oliveira et al. (77). In short, the experimental apparatus consisted of a gray rectangular open field $(60 \mathrm{~cm} \times 50 \mathrm{~cm} \times 26 \mathrm{~cm})$ with a visual cue placed on the arena wall. Prior to training, mice were handled for $1 \mathrm{~min} /$ day for 3 days. During the training day, mice received four $10 \mathrm{~min}$ training sessions. Between sessions, mice were placed back in their home cage for $3 \mathrm{~min}$. During the first session, mice were habituated to the gray rectangular open field in the absence of objects, but with an internal cue on one of the four walls. For the next three sessions, mice were placed in the same box but now with two distinct objects. The objects consisted of a glass bottle ( $100 \mathrm{~mL}$ volume) and a metal tower $\left(1.5625 \mathrm{in}^{2}\right)$. Mice were allowed to freely explore the environment and the objects for $10 \mathrm{~min}$. After $24 \mathrm{~h}$, mice were placed back in the rectangular environment for testing. The two objects were again present, but one of the two objects was now displaced to a novel spatial location. Mice were again allowed to freely explore the environment and the objects for $10 \mathrm{~min}$. Both the object identity and spatial location was balanced between subjects. The response to changing the spatial location was assessed by comparing the mean time the mice spent exploring the objects 

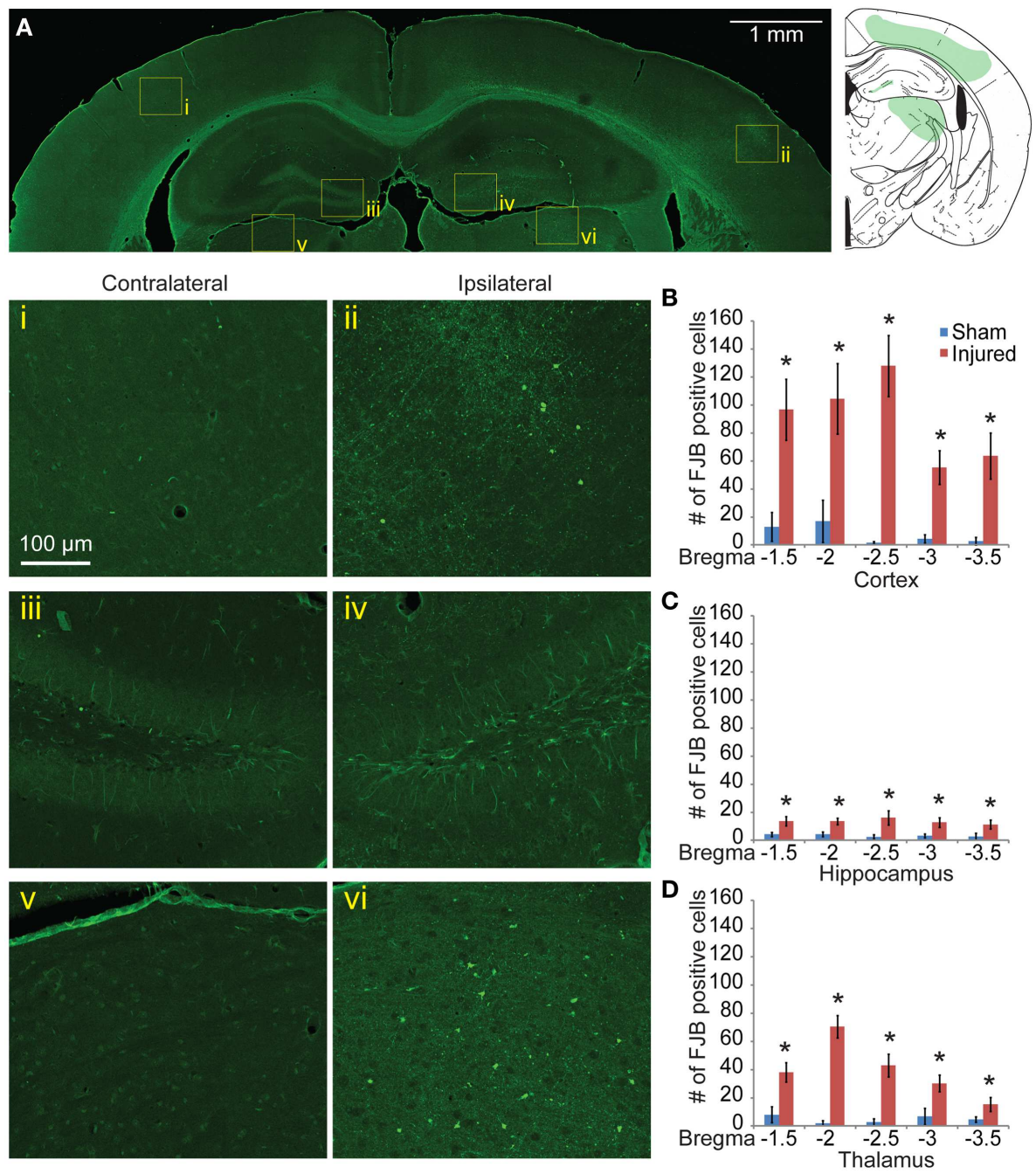

FIGURE 5 | Neuronal degeneration persists 8 days after mild controlled cortical impact. Eight days after injury, Fluoro-Jade B staining was located in the cortex (ii), dentate gyrus (iv), and thalamus (vi) (A). The contralateral regions did not show similar FJB staining (i, iii, v). (B) Degeneration in the cortex was still significantly elevated at 8 days compared to sham ( $p<0.001$ for all sections). (C) In the hippocampus, all sections show significant increase in FJB staining (bregma $-1.5 p=0.0105,-2.0$ $p=0.0018,-2.5 p=0.0102,-3.0 p=0.0058,-3.5 p=0.0338)$. (D) In the thalamus, all sections showed significant levels of FJB staining $(-1.5$ $p=0.0024,-2.0$ and $-2.5 p<0.001,-3.0 p=0.0081,-3.5 p=0.0323$ ). Samples sizes were $n=5$ for sham, $n=11$ for injured. Data are expressed as media \pm SEM. (when mice were facing and sniffing the objects within very close proximity and/or touching them) belonging to each category (displaced and non-displaced) in the test session minus the mean time spent in contact with the same object category in the last training session. A positive value indicates recognition of the spatial change.

In the CFC test, mice were placed in a testing chamber (Coulbourn, PA, USA) on training day for $3 \mathrm{~min}$. Two minutes and $28 \mathrm{~s}$ after the test started, mice were given a single $2 \mathrm{~s}, 1.5 \mathrm{~mA}$ shock. Twenty-four hours later, mice were placed in the same testing chamber and their percent freezing was calculated across the course of $5 \mathrm{~min}$.

\section{STATISTICAL ANALYSIS}

All statistical tests were carried out using JMP10. The variance among groups was first tested for normality (Shapiro-Wilks test) and then equality (Bartlett test). When the variance among groups was not similar, the two-sample $t$ test was used. Otherwise, a one way analysis of variance (ANOVA) was used. A linear regression model was used to look for significance between injured and uninjured groups. A repeated measures ANOVA was used in the rotarod behavior test.

\section{RESULTS}

\section{MILD CONTROLLED CORTICAL IMPACT INDUCES BLOOD-BRAIN BARRIER EXTRAVASATION}

The modification of the CCI technique produced little to no visible lesion and no visible hemorrhaging immediately after impact, but EB staining appeared throughout the lesion site (Figure 3A). Although some variability in the EB staining intensity occurred across separate animals, there was no difference in the spatial 

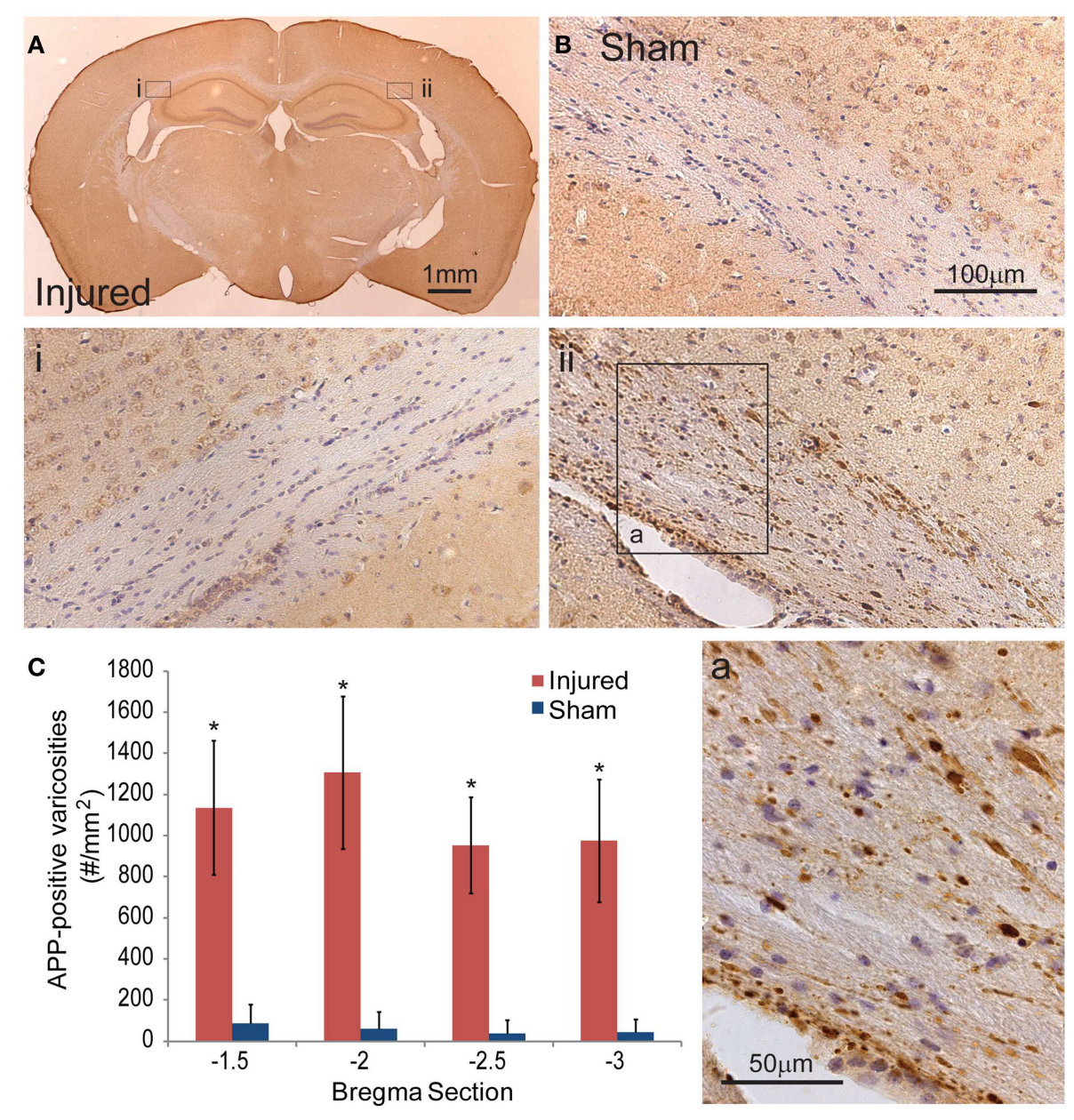

FIGURE 6 | Axonal injury appeared in the subcortical white matter after cortical impact injury. (A) The amyloid precusor protein (APP) staining in the subcortical white matter on the ipsilateral hemisphere (ii) show a number of varicosities (insert a). Contralateral (i) regions between injured and sham brains (B) do not show similar axonal pathologies. (C) Quantification of the axonal varicosities shows significant number of APP varicosities near and at the epicenter of impact ( $p<0.001$ for all three bregma sections, $n=5$ sham, $n=11$ injured). Data are expressed as media \pm SEM. distribution of EB staining. In the cortex, the staining formed an approximate hemispherical pattern. In comparison, a relatively higher concentration of EB staining appeared at the subcortical white matter directly below the impact site. In all animals tested, there was no staining in the cortical region directly contacting the impactor. In the hippocampus, the dorsal CA3 region (stratum pyramidale) and the dentate gyrus (some granular but mainly polymorphic layer) also showed staining. All injured animals had visible staining in the dentate across all five bregma sections analyzed. However, staining in the CA3 was only visible around bregma -1.5 and -2.0 . No EB staining was seen in any of the sham animals (Supplemental Figure 1) or on the contralateral side.

At higher magnification, many of the cells in these regions showed positive staining and were closely associated with the vasculature. Triple labeling with GFAP, Neurotrace ${ }^{\mathrm{TM}}$, and EB showed that across all regions of interest (cortex, dentate gyrus, and CA3), a majority of EB stained cells were neurons (Figures 3B-D), indicating a preferential uptake of the dye by neurons.

\section{MILD CONTROLLED CORTICAL IMPACT INDUCES NEURODEGENERATION PATTERNS THAT MATCHES THE EB PATTERNS AND PERSIST FOR AT LEAST 8 DAYS AFTER INJURY}

One day after injury, FJB staining showed a similar pattern to the EB staining (Figures 4Ai-vi), with a hemispherical degeneration pattern appearing immediately beneath the impact site. The cortical surface in direct contact with the indentor had no FJB staining. There was also elevated FJB staining in the subcortical white matter directly below the impact site. In the hippocampus, there were FJB positive cells in CA3 regions (stratum pyramidale) in bregma sections -1.5 and -2.0 but not in subsequent sections (Figure 4Avi). Staining in the dentate gyrus was apparent in all five bregma sections analyzed with the staining localized more to the polymorphic layer (Figure 4Av). Since FJB has been shown to co-label with astrocytes (78) sections were triple labeled with GFAP, FJB, and a fluorescent Nissl stain to determine which cell type(s) were FJB positive (data not shown). All FJB positive cells were positive for the Nissl stain and not GFAP. There was little to 

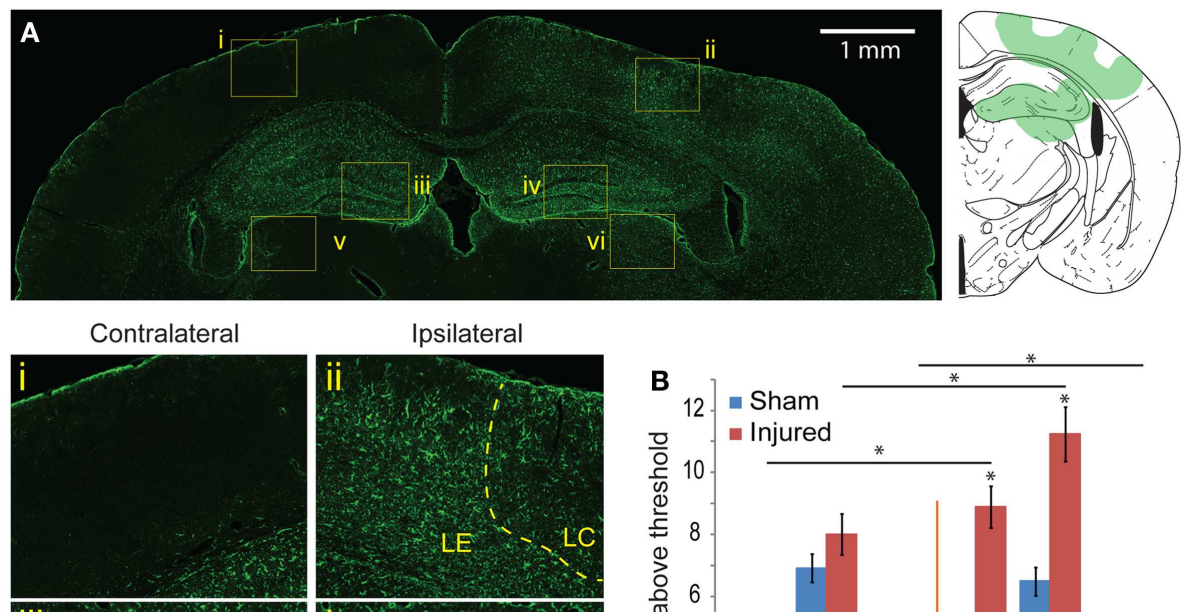

Ipsilateral
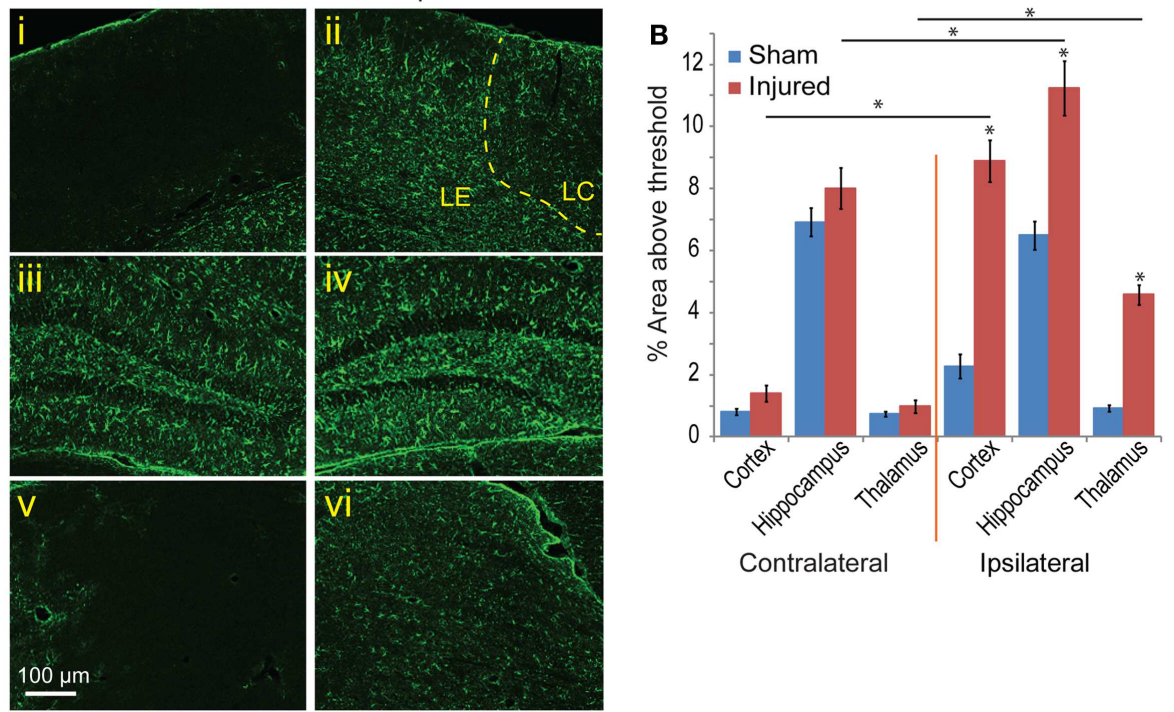

FIGURE 7 | Astrocyte reactivity is evident 8 days following mild cortical impact injury. (A) In the ipsilateral cortex, there was no prominent glial scar (ii), although there were clear regions of astrocyte reactivity. The lesion center (LC) also exhibited less GFAP expression than the lesion edge (LE). (i) The contralateral cortex did not significant GFAP staining. In the hippocampus, there was slight increase of GFAP expression in the ipsilateral compared to contralateral hemisphere [(iv) versus (iii)], especially in the dentate gyrus. The ipsilateral thalamus also saw an increased GFAP expression [(vi) versus (v)]. (B) Comparing the contralateral and ipsilateral GFAP expression averaged showed that astrocyte reactivity was significantly elevated in the injured hemisphere across all five sections ( $p<0.001$ for each brain region); between sham and injured on the ipsilateral side, there was a significant increase for all three brain regions $(p<0.0001)$. Sample size $n=5$ sham, $n=11$ injured. Data are expressed as media \pm SEM. no FJB stained positive cells in the sham and on the contralateral side (Figures $\mathbf{4 A i - i i i ) . ~ I n ~ t h e ~ s e c t i o n s ~ i m a g e d ~ a c r o s s ~ t h e ~ l e s i o n , ~}$ most showed significant levels of FJB positive cells between sham and injured animals (Figure 4B). Sections -1.5 to -3.0 showed significant FJB positive cells for both the cortex and hippocampus (cortex $p<0.001$ for each section -1.5 to -3.0 ; hippocampus $p=0.0113$ for section $1.5, p<0.001$ for sections -2.0 to -3.5 ). For section -3.5 , the cortex trended toward significance at $p=0.0635$.

Neurodegeneration indicated with FJB staining was sustained 8 days post injury, although the staining was reduced relative to $24 \mathrm{~h}$ labeling. Although the level of positively stained cells in the cortex was reduced (Figure 5A), the pattern of FJB positive cells was still similar to that seen in at the 24-h time point. The number of FJB positive cells was still significant compared to sham controls (for cortical degeneration, Figures 5Ai,ii,B, $p<0.001$ for all sections). Staining persisted in the CA3 and a significant retention of staining in the dentate gyrus appeared at this longer time point compared to sham (Figures 5Aiii,iv, C, bregma $-1.5=0.0105,-2.0 p=0.0018,-2.5 p=0.0102,-3.0$ $p=0.0058,-3.5 p=0.0338)$. A new area of significant labeling appeared in the thalamus at this timepoint (Figures 5Av,vi,D, bregma $-1.5 p=0.0024,-2.0$ and $-2.5 p<0.001,-3.0$ $p=0.0081,-3.5 p=0.0323$ ). A Nissl stain revealed no obvious neuronal loss in these regions (data not shown).

\section{MILD CONTROLLED CORTICAL IMPACT INDUCES AXONAL INJURY IN THE SUBCORTICAL WHITE MATTER}

To document the level of axonal injury, tissue at the 24-h survival time were labeled for APP (Figures 6A,B). To quantify the level of axonal injury, we looked at the density of axonal varicosity in injured animals. A significant number of axonal varicosities were seen on the ipsilateral side in comparison to sham and the contralateral side ( $p<0.001$ for all sections analyzed) (Figures 6Ai,ii,B,C). The number of varicosities decreased with distance from the immediate impact site. Varicosities in areas other than the corpus callosum were not seen. The axonal varicosities present at $24 \mathrm{~h}$ were no longer apparent at 8 days (data not shown).

\section{MILD CONTROLLED CORTICAL IMPACT PRODUCES INCREASE IN GLIOSIS THAT CLOSELY MATCH EB AND FJB PATTERNS}

To determine the glia response to this injury model, astrocyte and microglia localization and expression were analyzed. On the 

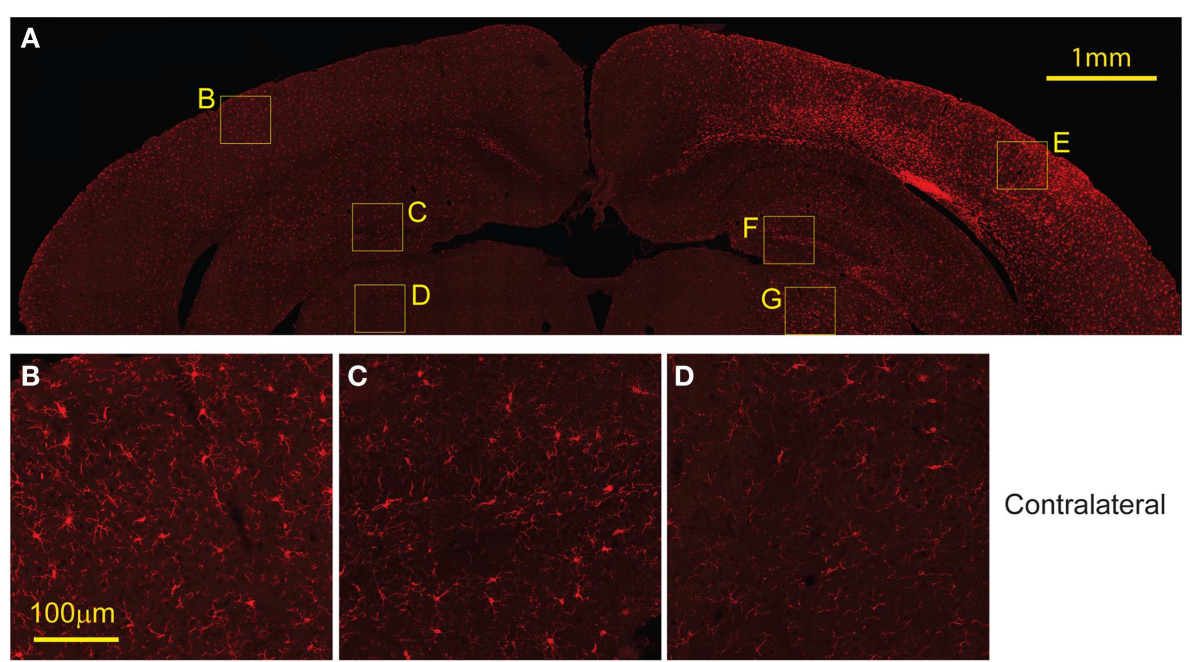

Contralateral
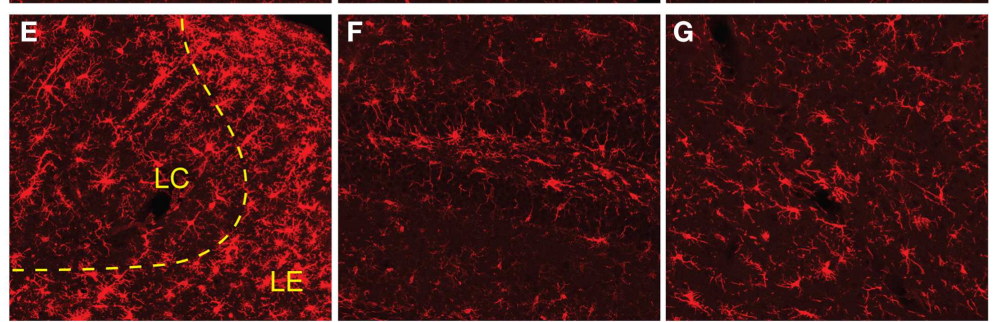

Ipsilateral

FIGURE 8 | Microglial activation occurs 8 days following injury

(A) The ipsilateral cortex showed increased microglia migration, especially to regions that also showed FJB staining at 8 days. The ipsilateral cortex showed greater presence of activated microglia in the lesion edge (LE) compared to the lesion center (LC) (E). (B) The contralateral cortex showed minimal microglia presence and no activated microglia. The ipsilateral hippocampus (F) and thalamus (G) show increased microglia migration compared to contralateral [hippocampus (C), thalamus (D)] but both had less presence of activated microglia compared to the cortex. Data are expressed as media \pm SEM. cortex of the ipsilateral side, Iba-1 and GFAP staining patterns were similar to the EB and FJB staining patterns at $24 \mathrm{~h}$ and 8 day (Figures 7Ai-vi). GFAP expression immediately under the impact site was less than the region surrounding, a pattern similar to that seen in EB and FJB. Increased GFAP expression in the cortex 8 days after injury was more diffusely elevated, with a general increase in GFAP expression throughout the cortex, even at distal regions, compared to the contralateral side. GFAP expression in the hippocampus was also significantly elevated, especially within and surrounding the dentate gyrus (Figures 7Aiii,iv). There was also a significant increase in GFAP expression in the thalamus (Figures 7Av,vi). Across all five bregma sections imaged, the average GFAP expression was significantly elevated when compared with sham and the contralateral side (Figure 7B, $p<0.001$ between cortex, hippocampus, and thalamus between sham and injured; $p<0.001$ between contralateral and ipsilateral for cortex and thalamus). This suggested that regions with localized $\mathrm{BBB}$ extravasation regions produce degeneration, later eliciting an inflammation response.

Similarly, staining for microglia with Iba-1 showed increased presence of microglia in the same regions with elevated GFAP expression, FJB, and EB labeling (Figure 8A). In the cortex, the region directly subject to impact showed increased microglia migration and the presence of some activated microglia. However, regions surrounding the directly impact site showed a higher presence of activated microglia (Figure 8E). Increased microglia presence was also found in the ipsilateral hippocampus and thalamus compared to the contralateral side (Figures 8F,G). There was no evidence of activated microglia or increased microglia presence on the contralateral side (Figures 8B-D).

\section{MILD CONTROLLED CORTICAL IMPACT PRODUCES SLIGHT BEHAVIORAL DEFICITS IN MOTOR DEPENDENT TASKS BUT NOT IN HIPPOCAMPAL DEPENDENT TASKS}

In all, mCCI produced very mild early behavioral deficits (Figure 9A). Injured mice showed vestibulomotor impairment after injury, as evident through the rotarod testing results. In repeated measures ANOVA showed significantly lower fault and fall times on the rotarod compared to sham mice $(p=0.0009$, 0.0017, respectively, Figure 9B). The interaction between time and injury was not significant but was significant for time alone $(p<0.0001)$ showing that injured animals did not learn at a different rate than sham animals. At $4-5$ days post injury, injured mice did not show a significant decreased preference for the displaced object than sham mice $(p=0.2345$, Figure 9C) in the hippocampus dependent behavioral task, SOR. Additionally, the CFC task administered 7-8 days post injury also failed to elicit significant behavioral difference between injured and sham mice $(p=0.2182$, Figure 9D). In all, mCCI produced early motor behavioral deficits. 


\section{A}

\begin{tabular}{|c|c|c|c|c|c|c|c|c|c|}
\hline Day -1 & Day 0 & Day 1 & Day 2 & Day 3 & Day 4 & Day 5 & Day 6 & Day 7 & Day 8 \\
\hline $\begin{array}{c}\mathrm{RR} \\
\text { training }\end{array}$ & $\mathrm{mCCl}$ & $\mathrm{RR}$ & $\mathrm{RR}$ & $\mathrm{RR}$ & $\begin{array}{c}\text { SOR } \\
\text { training }\end{array}$ & $\begin{array}{l}\text { SOR } \\
\text { test }\end{array}$ & & $\begin{array}{c}\mathrm{CFC} \\
\text { training }\end{array}$ & $\begin{array}{l}\text { CFC } \\
\text { test }\end{array}$ \\
\hline
\end{tabular}

B
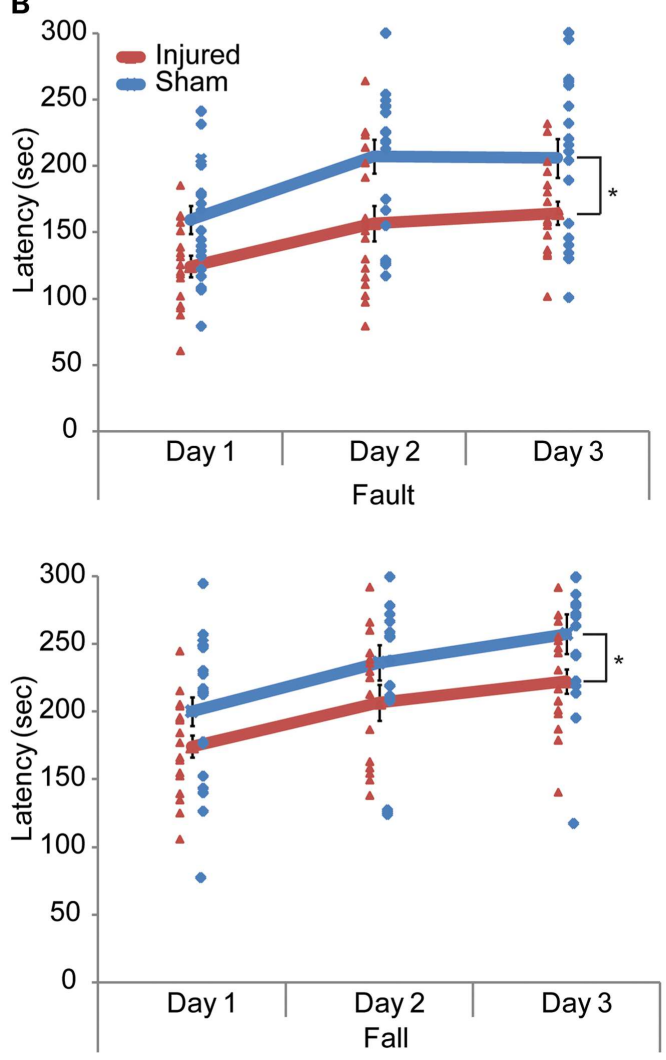

C

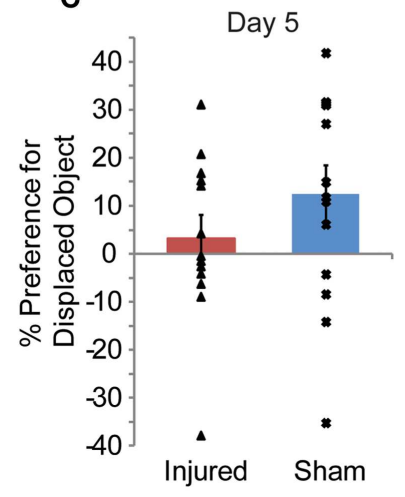

D

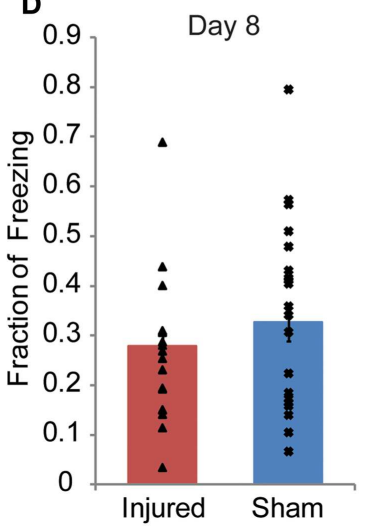

FIGURE 9 | Mild controlled cortical impact leads to a transient behavioral impairment. A behavioral testing paradigm to examine both cortical and hippocampal function after impact is shown in (A). Rotarod (RR) training occurred the day before injury; RR was given on days 1-3 post injury. Spatial object recognition (SOR) was implemented on days 4 (training) and 5 (test day). Contextual fear conditioning (CFC) was given on days 7 (training) and 8 (test). The animals were perfused on day 8 after CFC. The rotarod results (B) indicate injured animals faulted at lower speeds with significantly lower fault and fall latency times as determine by a repeated measures ANOVA ( $p=0.0009$ and 0.0017 , respectively). In neither the SOR (C) nor the CFC (D) ( $p=0.2345, p=0.2182$, respectively) did injured mice show significant level of altered behavior. Sample size $n=17$ sham, $n=19$ injured. Data are expressed as media \pm SEM.

\section{DISCUSSION}

The mild CCI model developed in this study produced early $(24 \mathrm{~h})$ and delayed ( 8 days) neurodegeneration, axonal injury in the subcortical white matter, and glial reactivity. These injuries appeared in conditions where the estimated tissue strain rates during impact were much less that the strain rates estimated for traditional cortical impact techniques (impact velocity: $4-6 \mathrm{~m} / \mathrm{s}$, strain rates: $400-1650 \mathrm{~s}^{-1}$ ). Early impairments in cortical motor function were the only behavioral deficits appearing in the mild CCI model. Later term measures of hippocampal function were not significantly different following injury, despite the brain showing broad areas of astrocyte and microglial reactivity. Together, these data show that re-creating the biomechanical conditions of mild TBI in the mouse brain led to an animal model of TBI that had very different histopathological and behavioral outcomes than the traditional cortical impact injury model.

Biomechanically, the mild controlled cortical impact studied herein shares some similarities to FPI injury. Both models have much slower loading rates than tCCI and produce injuries that are more in the range of human mTBI (Figure 1). While both models produce direct cortical deformation requiring craniotomies, loading on the brain between the two models is very different. FPI injury produces variable loading on the dura (79) whereas the indentor of a CCI provides a more consistent, repeatable deformation of the cortex. However, FPI injury offers a distinct advantage over cortical impact, as one can direct the injury to either a midline or lateral location (80). The midline FPI (MFPI) produces diffuse injuries, slight hemorrhages on the parieto-occipital cortex, 
corpus callosum, fimbria hippocampi, thalamus, and brainstem; high level injures produce similar but more extensive hemorrhaging patterns also encompassing the frontal, parietal, and occipital cortices $(81,82)$. Lateral FPI (LFPI) shares some features with the mild cortical impact technique developed in the study, since it produces focal injuries in addition to diffuse injuries. Moreover, mild LFPI produced BBB extravasation but the pattern was different than those of $\mathrm{mCCI}$, perhaps due to the more widespread distribution of fluid across the cortical surface (78). While both mild FPI and mCCI produced axonal damage, increased gliosis, and neuronal cell loss, the largest difference between the two models is in the correlation of injury patterns between each of the histopathological stains. In mCCI, the regions of gliosis, degeneration, and BBB extravasations were very similar, something that has never been noted for mild FPI injuries.

The more diverse histopathology of mild controlled cortical impact, in the absence of contusion, offers a new opportunity to study the mechanisms of injury in vivo and determine how they correlate to the tissue biomechanics of mild TBI. For example, evidence for immediate compromise of the plasma membrane (i.e., mechanoporation) after injury can be explored with mCCI, significantly extending past studies of this primary mechanism of injury following either cortical impact or FPI injury (83). The model studied in this paper is not complicated by the presence of hemorrhage or tissue tears, which can also contribute directly to membrane compromise and neuronal degeneration. Owing to the viscoelastic properties of the plasma membrane, high strain rate loading may lead to a lower tolerance to mechanoporation than at lower strain rates, where the membrane may accommodate deformation more easily without failing. Similarly, the changes in glutamate receptor physiology - e.g., both the loss of the NMDA receptor magnesium block and the loss of AMPA receptor desensitization $(62,84-86)$ - could be examined in the new model where the biomechanical conditions of mild TBI are more controllable.

A second area of research enabled by this mCCI model is defining the mechanical tolerance of the brain to repetitive injury. Past work suggests that repeated insults of the same magnitude will lead to more prolonged neurological deficits and cellular changes (87) with these changes even more pronounced if the second injury is delivered within 1 week of the initial injury (50, 88-90). However, defining the mechanical tolerance to repetitive injury is not easily addressed using past models, primarily because it is difficult to precisely control each insult. Past repeated head injury models, which have typically been closed head impact or FPI cannot be easily analyzed computationally making it difficult to determine biomechanical thresholds to a subsequent injury. With the mechanical design of our technique, our cortical impact modifications appear ideally suited to test the effect of repeated, precise mechanical insults to the brain. We are especially encouraged that the transient behavioral deficits appear after even single mild, low velocity insult because this insult may allow one to explore if these deficits are either more severe or more prolonged after repeat insults, as suggested by past work (50,88-90). In combination with finite element analysis of the tissue strains and strain rates that appear in areas of long term damage, we will likely start developing a more quantitative correlation among the biomechanics of injury, the tolerance of different brain regions to these injuries, and how these thresholds are modified with repetitive injury. In the long term, these correlations will be key in understanding protective strategies for the brain exposed to repeated insults, as well as providing more insights into the degenerating brain structure after repetitive insults of more complex origins.

\section{ACKNOWLEDGMENTS}

We thank Mr. Nikhil Mone for his help in part of meshing and modeling work. Funding was provided by grants from the National Institutes of Health and the New Jersey Commission for Brain Injury Research.

\section{SUPPLEMENTARY MATERIAL}

The Supplementary Material for this article can be found online at http://www.frontiersin.org/Journal/10.3389/fneur.2014.00100/ abstract

\section{REFERENCES}

1. National Center for Injury Prevention and Control. Report to Congress on Mild Traumatic Brain Injury in the United States: Steps to Prevent a Serious Public Health Problem. Atlanta, GA: Centers for Disease Control and Prevention (2003).

2. Dikmen S, Machamer J, Temkin N. Mild head injury: facts and artifacts. J Clin Exp Neuropsychol (2001) 23:729-38. doi:10.1076/jcen.23.6.729.1019

3. Signoretti S, Vagnozzi R, Tavazzi B, Lazzarino G. Biochemical and neurochemical sequelae following mild traumatic brain injury: summary of experimental data and clinical implications. Neurosurg Focus (2010) 29:E1. doi:10.3171/2010. 9.FOCUS10183

4. Hamilton NA, Keller MS. Mild traumatic brain injury in children. Semin Pediatr Surg (2010) 19:271-8. doi:10.1053/j.sempedsurg.2010.06.005

5. Teasdale G, Jennett B. Assessment of coma and impaired consciousness: a practical scale. Lancet (1974) 304:81-4. doi:10.1016/S0140-6736(74)91639-0

6. Malec JF, Brown AW, Leibson CL, Flaada JT, Mandrekar JN, Diehl NN, et al. The mayo classification system for traumatic brain injury severity. J Neurotrauma (2007) 24:1417-24. doi:10.1089/neu.2006.0245

7. Saatman KE, Duhaime A-C, Bullock R, Maas AI, Valadka A, Manley GT. Classification of traumatic brain injury for targeted therapies. J Neurotrauma (2008) 25:719-38. doi:10.1089/neu.2008.0586

8. Lee B, Newberg A. Neuroimaging in traumatic brain imaging. NeuroRx (2005) 2:372-83. doi:10.1602/neurorx.2.2.372

9. Le TH, Gean AD. Neuroimaging of traumatic brain injury. Mt Sinai J Med J Transl Pers Med (2009) 76:145-62. doi:10.1002/msj.20102

10. Bigler ED, Maxwell WL. Neuropathology of mild traumatic brain injury: relationship to neuroimaging findings. Brain Imaging Behav (2012) 6:108-36. doi:10.1007/s11682-011-9145-0

11. Powell JM, Ferraro JV, Dikmen SS, Temkin NR, Bell KR. Accuracy of mild traumatic brain injury diagnosis. Arch Phys Med Rehabil (2008) 89:1550-5. doi:10.1016/j.apmr.2007.12.035

12. Ruff RM, Iverson GL, Barth JT, Bush SS, Broshek DK, NAN Policy and Planning Committee. Recommendations for diagnosing a mild traumatic brain injury: a national academy of neuropsychology education paper. Arch Clin Neuropsychol (2009) 24:3-10. doi:10.1093/arclin/acp006

13. McKinlay A. Controversies and outcomes associated with mild traumatic brain injury in childhood and adolescences. Child Care Health Dev (2010) 36:3-21. doi:10.1111/j.1365-2214.2009.01006.x

14. Yeates KO. Mild traumatic brain injury and postconcussive symptoms in children and adolescents. J Int Neuropsychol Soc (2010) 16:953-60. doi:10.1017/ S1355617710000986

15. Beauchamp K, Mutlak H, Smith WR, Shohami E, Stahel PF. Pharmacology of traumatic brain injury: where is the "golden bullet"? Mol Med (2008) 14:731. doi:10.2119/2008-00050.Beauchamp

16. Ward CC, Thompson RB. The Development of a Detailed Finite Element Brain Model. Warrendale, PA: SAE International (1975).

17. Willinger R, Kang HS, Diaw B. Three-dimensional human head finite-element model validation against two experimental impacts. Ann Biomed Eng (1999) 27:403-10. doi:10.1114/1.165 
18. Ruan JS, Khalil T, King AI. Dynamic response of the human head to impact by three-dimensional finite element analysis. J Biomech Eng (1994) 116:44-50. doi:10.1115/1.2895703

19. Levchakov A, Linder-Ganz E, Raghupathi R, Margulies SS, Gefen A. Computational studies of strain exposures in neonate and mature rat brains during closed head impact. J Neurotrauma (2006) 23:1570-80. doi:10.1089/neu.2006.23.1570

20. Viano DC, Casson IR, Pellman EJ, Zhang L, King AI, Yang KH. Concussion in professional football: brain responses by finite element analysis: part 9. Neurosurgery (2005) 57:891-916. doi:10.1227/01.NEU.0000186950.54075.3B

21. Viano DC, Pellman EJ. Concussion in professional football: biomechanics of the striking player - part 8. Neurosurgery (2005) 56:266-80. doi:10.1227/01.NEU. $0000150035.54230 .3 \mathrm{C}$

22. Viano DC, Casson IR, Pellman EJ. Concussion in professional football. Neurosurgery (2007) 61:313-28. doi:10.1227/01.NEU.0000279969.02685.D0

23. Meaney D, Thibault LE. Physical Model Studies of Cortical Brain Deformation in Response to High Strain Rate Inertial Loading. Lyon: International Conference on the Biomechanics of Impacts (1990). p. 215-24.

24. Margulies SS, Thibault LE, Gennarelli TA. Physical model simulations of brain injury in the primate. J Biomech (1990) 23:823-36. doi:10.1016/0021-9290(90) 90029-3

25. Margulies SS, Thibault LE. A proposed tolerance criterion for diffuse axonal injury in man. J Biomech (1992) 25:917-23. doi:10.1016/0021-9290(92) 90231-O

26. Shreiber DI, Bain AC, Meaney DF. In vivo Thresholds for Mechanical Injury to the Blood-Brain Barrier. Warrendale, PA: SAE International (1997).

27. Bain AC, Meaney DF. Thresholds for Mechanical Injury to the in vivo White Matter. Warrendale, PA: SAE International (1999).

28. Bain AC, Meaney DF. Tissue-level thresholds for axonal damage in an experimental model of central nervous system white matter injury. J Biomech Eng (2000) 122:615-22. doi:10.1115/1.1324667

29. Morrison B III, Meaney DF, Margulies SS, McIntosh TK. Dynamic mechanical stretch of organotypic brain slice cultures induces differential genomic expression: relationship to mechanical parameters. J Biomech Eng (2000) 122(3):224-30. doi:10.1115/1.429650

30. Morrison B III, Cater HL, Wang CC-B, Thomas FC, Hung CT, Ateshian GA, et al. A tissue level tolerance criterion for living brain developed with an in vitro model of traumatic mechanical loading. Stapp Car Crash J (2003) 47:93-105.

31. Morrison B III, Cater HL, Benham CD, Sundstrom LE. An in vitro model of traumatic brain injury utilising two-dimensional stretch of organotypic hippocampal slice cultures. J Neurosci Methods (2006) 150:192-201. doi:10.1016/j. jneumeth.2005.06.014

32. Singh A, Lu Y, Chen C, Kallakuri S, Cavanaugh JM. A new model of traumatic axonal injury to determine the effects of strain and displacement rates. Stapp Car Crash J (2006) 50:601-23.

33. Elkin BS, Morrison B III. Region-specific tolerance criteria for the living brain. Stapp Car Crash J (2007) 51:127-38.

34. Bayly PV, Black EE, Pedersen RC, Leister EP, Genin GM. In vivo imaging of rapid deformation and strain in an animal model of traumatic brain injury. J Biomech (2006) 39:1086-95. doi:10.1016/j.jbiomech.2005.02.014

35. Pfister BJ, Weihs TP, Betenbaugh M, Bao G. An in vitro uniaxial stretch model for axonal injury. Ann Biomed Eng (2003) 31:589-98. doi:10.1114/1.1566445

36. Rashid B, Destrade M, Gilchrist MD. Mechanical characterization of brain tissue in tension at dynamic strain rates. J Mech Behav Biomed Mater (2012) 33:43-54. doi:10.1016/j.jmbbm.2012.07.015

37. Zhang L, Yang KH, King AI. A proposed injury threshold for mild traumatic brain injury. J Biomech Eng (2004) 126:226-36. doi:10.1115/1.1691446

38. Ruan JS, Khalil TB, King AI. Finite Element Modeling of Direct Head Impact. Warrendale, PA: SAE International (1993).

39. McAllister TW, Ford JC, Ji S, Beckwith JG, Flashman LA, Paulsen K, et al. Maximum principal strain and strain rate associated with concussion diagnosis correlates with changes in corpus callosum white matter indices. Ann Biomed Eng (2012) 40:127-40. doi:10.1007/s10439-011-0402-6

40. Kleiven S. Predictors for traumatic brain injuries evaluated through accident reconstructions. Stapp Car Crash J (2007) 51:81-114.

41. Kimpara H, Iwamoto M. Mild traumatic brain injury predictors based on angular accelerations during impacts. Ann Biomed Eng (2012) 40:114-26. doi:10.1007/s10439-011-0414-2

42. Dokko Y, Anderson R, Manavis J, Blumburgs P, McLean J, Zhang L, et al. Validation of the human head FE model against pedestrian accident and its tentative application to the examination of the existing tolerance curve. In: The 18th International Technical Conference on the Enhanced Safety of Vehicles (ESV) Proceedings. Nagoya (2003). p. 19-22. Available from: http://www-nrd.nhtsa.dot. gov/pdf/esv/esv18/cd/files/18ESV-000322.pdf

43. Meaney DF, Smith DH, Shreiber DI, Bain AC, Miller RT, Ross DT, et al. Biomechanical analysis of experimental diffuse axonal injury. J Neurotrauma (1995) 12:689-94. doi:10.1089/neu.1995.12.689

44. Shreiber DI, Bain AC, Ross DT, Smith DH, Gennarelli TA, McIntosh TK, et al. Experimental investigation of cerebral contusion: histopathological and immunohistochemical evaluation of dynamic cortical deformation. J Neuropathol Exp Neurol (1999) 58:153-64. doi:10.1097/00005072-19990200000005

45. Thibault LE, Meaney DF, Anderson BJ, Marmarou A. Biomechanical aspects of a fluid percussion model of brain injury. J Neurotrauma (1992) 9:311-22. doi:10.1089/neu.1992.9.311

46. Feeney DM, Boyeson MG, Linn RT, Murray HM, Dail WG. Responses to cortical injury: I. Methodology and local effects of contusions in the rat. Brain Res (1981) 211:67-77. doi:10.1016/0006-8993(81)90067-6

47. Shohami E, Shapira Y, Cotev S. Experimental closed head injury in rats: prostaglandin production in a noninjured zone. Neurosurgery (1988) 22:859-63. doi:10.1227/00006123-198805000-00009

48. Chen Y, Constantini S, Trembovler V, Weinstock M, Shohami E. An experimental model of closed head injury in mice: pathophysiology, histopathology, and cognitive deficits. J Neurotrauma (1996) 13:557-68.

49. Marmarou A, Foda MA, van den Brink W, Campbell J, Kita H, Demetriadou K. A new model of diffuse brain injury in rats. Part I: pathophysiology and biomechanics. J Neurosurg (1994) 80:291-300. doi:10.3171/jns.1994.80.2.0291

50. Longhi L, Saatman KE, Fujimoto S, Raghupathi R, Meaney DF, Davis J, et al. Temporal window of vulnerability to repetitive experimental concussive brain injury. Neurosurgery (2005) 56:364-74. doi:10.1227/01.NEU.0000149008.73513.44

51. Ellingson BM, Fijalkowski RJ, Pintar FA, Yoganandan N, Gennarelli TA. New mechanism for inducing closed head injury in the rat. Biomed Sci Instrum (2005) 41:86-91.

52. Fijalkowski RJ, Stemper BD, Pintar FA, Yoganandan N, Crowe MJ, Gennarelli TA. New rat model for diffuse brain injury using coronal plane angular acceleration. J Neurotrauma (2007) 24:1387-98. doi:10.1089/neu.2007.0268

53. Kilbourne M, Kuehn R, Tosun C, Caridi J, Keledjian K, Bochicchio G, et al. Novel model of frontal impact closed head injury in the rat. J Neurotrauma (2009) 26:2233-43. doi:10.1089/neu.2009.0968

54. Creed JA, DiLeonardi AM, Fox DP, Tessler AR, Raghupathi R. Concussive brain trauma in the mouse results in acute cognitive deficits and sustained impairment of axonal function. J Neurotrauma (2011) 28:547-63. doi:10.1089/neu. 2010.1729

55. Albert-Weissenberger C, Várrallyay C, Raslan F, Kleinschnitz C, Sirén A-L. An experimental protocol for mimicking pathomechanisms of traumatic brain injury in mice. Exp Transl Stroke Med (2012) 4:1. doi:10.1186/2040-73784- 1

56. Fijalkowski RJ, Yoganandan N, Zhang J, Pintar FA. A finite element model of region-specific response for mild diffuse brain injury. Stapp Car Crash J (2009) 53:193-213.

57. Blumbergs PC, Scott G, Manavis J, Wainwright H, Simpson DA, McLean AJ. Staining of amyloid percursor protein to study axonal damage in mild head injury. Lancet (1994) 344:1055-6. doi:10.1016/S0140-6736(94)91712-4

58. Blumbergs PC, Scott G, Manavis J, Wainwright H, Simpson DA, McLean AJ. Topography of axonal injury as defined by amyloid precursor protein and the sector scoring method in mild and severe closed head injury. J Neurotrauma (1995) 12:565-72. doi:10.1089/neu.1995.12.565

59. Cloots RJ, van Dommelen JA, Kleiven S, Geers MG. Multi-scale mechanics of traumatic brain injury: predicting axonal strains from head loads. Biomech Model Mechanobiol (2013) 12:137-50. doi:10.1007/s10237-012-0387-6

60 . Ho J, Kleiven S. Dynamic response of the brain with vasculature: a threedimensional computational study. J Biomech (2007) 40:3006-12. doi:10.1016/j. jbiomech.2007.02.011

61. Kleiven S, Hardy WN. Correlation of an FE model of the human head with local brain motion-consequences for injury prediction. Stapp Car Crash J (2002) 46:123-44.

62. Zhang L, Yang KH, Dwarampudi R, Omori K, Li T, Chang K, et al. Recent advances in brain injury research: a new human head model development and validation. Stapp Car Crash J (2001) 45:369-94. 
63. Zhang L, Bae J, Hardy WN, Monson KL, Manley GT, Goldsmith W, et al. Computational study of the contribution of the vasculature on the dynamic response of the brain. Stapp Car Crash J (2002) 46:145-64.

64. Zhang L, Yang KH, King AI, Viano DV. A new biomechanical predictor for mild traumatic brain injury-A preliminary finding. In: Proceeding 2003 Summer Bioengineering Conference (2003). p. 137-8. Available from: http://www.tulane.edu/ $\sim$ sbc2003/pdfdocs/0137.PDF

65. Yoganandan N, Li J, Zhang J, Pintar FA, Gennarelli TA. Influence of angular acceleration-deceleration pulse shapes on regional brain strains. J Biomech (2008) 41:2253-62. doi:10.1016/j.jbiomech.2008.04.019

66. Miller RT, Margulies SS, Leoni M, Nonaka M, Chen X, Smith DH, et al. Finite Element Modeling Approaches for Predicting Injury in an Experimental Model of Severe Diffuse Axonal Injury. Warrendale, PA: SAE International (1998). Available from: http://papers.sae.org/983154/

67. Mao H, Jin X, Zhang L, Yang KH, Igarashi T, Noble-Haeusslein LJ, et al. Finite element analysis of controlled cortical impact-induced cell loss. J Neurotrauma (2010) 27:877-88. doi:10.1089/neu.2008.0616

68. Mao H, Zhang L, Yang KH, King AI. Application of a finite element model of the brain to study traumatic brain injury mechanisms in the rat. Stapp Car Crash J (2006) 50:583-600.

69. Meaney DF, Ross DT, Winkelstein BA, Brasko J, Goldstein D, Bilston LB, et al. Modification of the cortical impact model to produce axonal injury in the rat cerebral cortex. J Neurotrauma (1994) 11:599-612. doi:10.1089/neu.1994. 11.599

70. Peña A, Pickard JD, Stiller D, Harris NG, Schuhmann MU. Brain tissue biomechanics in cortical contusion injury: a finite element analysis. Acta Neurochir Suppl (2005) 95:333-6. doi:10.1007/3-211-32318-X_68

71. Mao H, Yang KH, King AI, Yang K. Computational neurotrauma - design, simulation, and analysis of controlled cortical impact model. Biomech Model Mechanobiol (2010) 9:763-72. doi:10.1007/s10237-010-0212-z

72. Smith DH, Soares HD, Pierce JS, Perlman KG, Saatman KE, Meaney DF, et al. A model of parasagittal controlled cortical impact in the mouse: cognitive and histopathologic effects. J Neurotrauma (1995) 12:169-78. doi:10.1089/neu.1995. 12.169

73. Pleasant JM, Carlson SW, Mao H, Scheff SW, Yang KH, Saatman KE. Rate of neurodegeneration in the mouse controlled cortical impact model is influenced by impactor tip shape: implications for mechanistic and therapeutic studies. J Neurotrauma (2011) 28:2245-62. doi:10.1089/neu.2010.1499

74. Lusardi TA, Rangan J, Sun D, Smith DH, Meaney DF. A device to study the initiation and propagation of calcium transients in cultured neurons after mechanical stretch. Ann Biomed Eng (2004) 32:1546-58. doi:10.1114/B:ABME.0000049038. 75368.75

75. Cernak I. Animal models of head trauma. NeuroRx (2005) 2:410-22. doi:10. 1602/neurorx.2.3.410

76. Oliveira AM, Estévez MA, Hawk JD, Grimes S, Brindle PK, Abel T. Subregionspecific p300 conditional knock-out mice exhibit long-term memory impairments. Learn Mem (2011) 18:161-9. doi:10.1101/lm.1939811

77. Oliveira AM, Hawk JD, Abel T, Havekes R. Post-training reversible inactivation of the hippocampus enhances novel object recognition memory. Learn Mem (2010) 17:155-60. doi:10.1101/lm.1625310

78. Anderson KJ, Fugaccia I, Scheff SW. Fluoro-Jade B stains quiescent and reactive astrocytes in the rodent spinal cord. J Neurotrauma (2003) 20:1223-31. doi: $10.1089 / 089771503770802899$

79. Dixon CE, Lighthall JW, Anderson TE. Physiologic, histopathologic, and cineradiographic characterization of a new fluid-percussion model of experimental brain injury in the rat. J Neurotrauma (1988) 5:91-104. doi:10. 1089/neu.1988.5.91

80. Thompson HJ, Lifshitz J, Marklund N, Grady MS, Graham DI, Hovda DA, et al. Lateral fluid percussion brain injury: a 15-year review and evaluation. J Neurotrauma (2005) 22:42-75. doi:10.1089/neu.2005.22.42

81. Dixon CE, Lyeth BG, Povlishock JT, Findling RL, Hamm RJ, Marmarou A, et al. A fluid percussion model of experimental brain injury in the rat. J Neurosurg (1987) 67:110-9. doi:10.3171/jns.1987.67.1.0110

82. McIntosh TK, Noble L, Andrews B, Faden AI. Traumatic brain injury in the rat: characterization of a midline fluid-percussion model. Cent Nerv Syst Trauma (1987) 4:119-34.

83. Farkas O, Lifshitz J, Povlishock JT. Mechanoporation induced by diffuse traumatic brain injury: an irreversible or reversible response to injury? J Neurosci (2006) 26:3130-40. doi:10.1523/JNEUROSCI.5119-05.2006

84. Goforth PB, Ellis EF, Satin LS. Enhancement of AMPA-mediated current after traumatic injury in cortical neurons. J Neurosci (1999) 19:7367-74.

85. Patel TP, Ventre SC, Geddes-Klein D, Singh PK, Meaney DF. Single-neuron NMDA receptor phenotype influences neuronal rewiring and reintegration following traumatic injury. J Neurosci (2014) 34:4200-13. doi:10.1523/ JNEUROSCI.4172-13.2014

86. Singh P, Doshi S, Spaethling JM, Hockenberry AJ, Patel TP, Geddes-Klein DM, et al. N-methyl-d-aspartate receptor mechanosensitivity is governed by $\mathrm{C}$ terminus of NR2B subunit. J Biol Chem (2012) 287:4348-59. doi:10.1074/jbc.M111. 253740

87. Laurer HL, Bareyre FM, Lee VM, Trojanowski JQ, Longhi L, Hoover R, et al. Mild head injury increasing the brain's vulnerability to a second concussive impact. J Neurosurg (2001) 95:859-70. doi:10.3171/jns.2001.95.5.0859

88. Bennett RE, Mac Donald CL, Brody DL. Diffusion tensor imaging detects axonal injury in a mouse model of repetitive closed-skull traumatic brain injury. $\mathrm{Neu}$ rosci Lett (2012) 513:160-5. doi:10.1016/j.neulet.2012.02.024

89. Shitaka Y, Tran HT, Bennett RE, Sanchez L, Levy MA, Dikranian K, et al. Repetitive closed-skull traumatic brain injury in mice causes persistent multifocal axonal injury and microglial reactivity. J Neuropathol Exp Neurol (2011) 70:551-67. doi:10.1097/NEN.0b013e31821f891f

90. Shultz SR, MacFabe DF, Foley KA, Taylor R, Cain DP. A single mild fluid percussion injury induces short-term behavioral and neuropathological changes in the Long-Evans rat: support for an animal model of concussion. Behav Brain Res (2011) 224:326-35. doi:10.1016/j.bbr.2011.06.012

Conflict of Interest Statement: The authors declare that the research was conducted in the absence of any commercial or financial relationships that could be construed as a potential conflict of interest.

Received: 23 April 2014; accepted: 03 June 2014; published online: 18 June 2014.

Citation: Chen Y, Mao H, Yang KH, Abel T and Meaney DF (2014) A modified controlled cortical impact technique to model mild traumatic brain injury mechanics in mice. Front. Neurol. 5:100. doi: 10.3389/fneur.2014.00100

This article was submitted to Neurotrauma, a section of the journal Frontiers in Neurology.

Copyright (c) 2014 Chen, Mao, Yang, Abel and Meaney. This is an open-access article distributed under the terms of the Creative Commons Attribution License (CC BY). The use, distribution or reproduction in other forums is permitted, provided the original author(s) or licensor are credited and that the original publication in this journal is cited, in accordance with accepted academic practice. No use, distribution or reproduction is permitted which does not comply with these terms. 